\title{
Physicochemical Properties of Red Beetroot and Quince Fruit Extracts Instant Beverage Powder: Effect of Drying Method and Maltodextrin Concentration
}

\author{
Marziyeh Hajiaghaei and Akram Sharifi \\ Department of Food Science and Technology, Faculty of Industrial and Mechanical Engineering, Qazvin Branch, \\ Islamic Azad University, Qazvin, Iran \\ Correspondence should be addressed to Akram Sharifi; asharifi81@gmail.com
}

Received 4 October 2021; Accepted 14 December 2021; Published 4 January 2022

Academic Editor: Rita Celano

Copyright ( 92022 Marziyeh Hajiaghaei and Akram Sharifi. This is an open access article distributed under the Creative Commons Attribution License, which permits unrestricted use, distribution, and reproduction in any medium, provided the original work is properly cited.

In this study, production of instant beverage powder by the foam-mat drying method (foam-mat freeze- and hot-air drying) from red beetroot, quince fruit, and cinnamon extracts without and with maltodextrin (MD) $(0 \%, 10 \%, 20 \%$, and $30 \%)$ were investigated. The results showed that an increase in the MD level has led to a decrease in the moisture content of powders. Drying method and MD concentration had a significant effect on rehydration time, color, and total phenolic content $(p \leq 0.05)$. Foammat hot-air-dried powder containing $20 \% \mathrm{MD}$ had a good flowability. According to the statistical analysis, MD content had a more significant effect on the antioxidant activity of powders than the drying method $(p \leq 0.05)$. The total phenolic content of foam-mat hot-air-dried powders was higher than that of foam-mat freeze-dried powders. Based on the results, the produced powder containing $20 \% \mathrm{MD}$ via foam-mat hot-air drying $\left(60^{\circ} \mathrm{C}\right)$ was the optimum sample.

\section{Introduction}

This research has focused on preparing instant beverage powder based on red beetroot extract. Instant beverage powder is a convenient way to make drinks, by simply adding either hot or cold water [1]. Red beetroots are a rich source of polyphenols, antioxidants, vitamins, carotenoids, flavonoids, and minerals [2]. Beetroot supplementation can serve as a beneficial strategy to boost internal antioxidant defenses [3]. As a source of nitrate, beetroot ingestion supplies an indigenous means of augmenting in vivo nitric oxide (NO) availability and has emerged as a potential approach to prevent and manage pathologies associated with reduced NO bioavailability, especially hypertension and endothelial function [3]. Betanin or beetroot red is one of the betalains color dyes that is liable for the purplish-red color of the beet [4]. Betalains are water-soluble pigments containing nitrogen. Malic acid is reported as the most abundant organic acid in beetroot juice and other beetroot products, followed by citric acid and ascorbic acid [2]. Another remarkable characteristic of the beet is its different flavor. Geosmin is a chemical that causes the specific earthy aroma of beets [2]; so, in this study, quince and cinnamon extracts were also used to improve the aroma and flavor of the red beetroot extract-based instant beverage powder as well as increasing its nutritional value.

Quince fruit (Cydonia oblonga Miller, Rosaceae family) contains several phenolic compounds, which along with ascorbic and citric acid contribute to its antioxidant activity. A large number of volatile compounds in quince fruit are responsible for its special fragrance [6]. Cinnamon derives from the internal bark of tropical evergreen cinnamon trees [7]. The major compounds isolated and identified in cinnamon belong to two chemical types: polyphenols and volatile phenols [8]. Cinnamaldehyde is liable for the flavor and aroma of cinnamon [7].

Drying is an important method to preserve raw food materials [9]. Of the methods used to produce powdered 
food products, drying by foam layer (foam-mat drying) is noteworthy. This method consists of the conversion of liquid or semiliquid foods into stable foams via intense agitation and insertion of air, along with using foaming agents and stabilizers [9]. As liquid foams are metastable, the use of stabilizing agents is needed, which are usually surfactant molecules. The stabilizers delay the several mechanisms of foam aging such as drainage, coalescence, and coarsening [10]. Some foam stabilizers include xanthan gum, propylene glycol alginate (PGA), methylcellulose, Arabic gum, and maltodextrin. In foam-mat drying, the process of drying usually refers to dehydration of the thin layer of foam by hot air. Besides foammat hot-air drying, other methods of drying include freezedrying, vacuum-drying, infrared-drying, and microwavedrying have also been reported $[11,12]$.

Production of barberry (Berberis vulgaris) extract powder [1], foam-mat freeze-drying of date powder [13], foam-mat drying of jambolan [Syzygium cumini (L.)] juice [14], and development of beetroot (Beta vulgaris) powder using foam-mat drying [4] are some of the research studies that had been conducted in this field.

This study aimed to evaluate the influence of the addition of maltodextrin as well as the effect of the drying method (foam-mat freeze- or hot-air drying) on some of the physicochemical properties of the beverage powders based on red beetroot, quince fruit, and cinnamon extracts.

\section{Material and Methods}

Red beetroot (Beta vulgaris L. ssp. vulgaris) and quince fruit (Cydonia oblonga Miller) were obtained from a local market in Qazvin, Iran, in November 2019. Samples were uniform in size and shape and free from physical and insect damages. The cinnamon (Cinnamomum verum) extract was purchased from Zardband company (Yasuj city, Iran). Maltodextrin (MD) (DE 20), Folin-Ciocalteu reagent, gallic acid, methanol, albumin powder, and sodium carbonate were purchased from Merck (Darmstadt, Germany), and 2,2diphenyl-1-picrylhydrazyl (DPPH) was acquired from Sigma-Aldrich (St. Louis, MO, USA).

Beetroot and quince fruit extracts were prepared according to the procedure described by Slavov et al. (2013) with some modifications [15]. For this purpose, washed and sanitized red beetroot and quince fruit pieces were pressed with a centrifugal juicer (Santos Juicer, Lyon, France) at $3500 \mathrm{rpm}$ separately, and the residual pomace was used for the extraction of their residual extract. The extraction procedure was done two times with different ratios of pomace to water, $1: 4$ and $1: 2$, respectively at room temperature in the dark $(1 \mathrm{~h}$ for the first extraction and $0.5 \mathrm{~h}$ for subsequent extraction).

2.1. Extracts Experiments. The red beetroot, quince fruit, and cinnamon extracts were mixed in ratio of $75: 24: 1(\% \mathrm{w} / \mathrm{w})$ and used to determine the moisture content, $\mathrm{pH}$, and total soluble solids (degree Brix) [16].

2.2. Preparation of Foam. For the preparation of foam, a constant level of $3 \%$ albumin powder and $0,10,20$, and $30 \%$ (\%w/w) MD were added to the mixed extracts and whipped using a blender (IKA Labortechnik, Germany) at maximum speed $(788 \mathrm{rpm})$ for 8 minutes. The foam prepared with $0 \%$ maltodextrin was used as a control sample.

\subsection{Foam Experiments}

2.3.1. Foam Expansion. The prepared $50 \mathrm{~g}$ foam was poured into a graduated cylinder, and its volume was measured [4]. The foam expansion was calculated using equation (1):

$$
\% \text { foam expansion }=\frac{V_{1}-V_{0}}{V_{0}} \times 100,
$$

where $V_{1}$ is final foam volume $\left(\mathrm{cm}^{3}\right)$ and $V_{0}$ is the initial extract volume.

2.3.2. Foam Density. The prepared foam was transported to a measuring cylinder without foam structure collapse or trapping air bubbles [17]. The foam density was determined using equation (2):

$$
\text { foam density }=\frac{\text { mass of foam }(g)}{\text { volume of foam }\left(\mathrm{cm}^{3}\right)}
$$

2.3.3. Foam Stability. The prepared foam was poured into a graduated cylinder and kept at room temperature for 3 hours [18]. Foam stability was calculated using

$$
\text { foam stability }(\%)=\frac{V_{\text {foam }}}{V_{0}} \times 100,
$$

where $V_{\text {foam }}$ is the final foam volume $\left(\mathrm{cm}^{3}\right)$ and $V_{0}$ is the initial foam volume of the experiment (zero time) $\left(\mathrm{cm}^{3}\right)$.

2.4. Drying Processes. For foam-mat hot-air-drying, the foam samples were spread (constant thickness of $5 \mathrm{~mm}$ ) on glass plates and put into a convection drying oven $(\mathrm{SH}-$ Scientific, Republic of Korea) at $60^{\circ} \mathrm{C}$ and a superficial air velocity of $1.5 \mathrm{~m} / \mathrm{s}$. Drying was continued until constant weight is achieved [4].

In the foam-mat freeze-drying method, foam samples were spread on glass plates at a foam thickness of $5 \mathrm{~mm}$ and, after deep-freezing, subjected to freeze-drying (Zist Farayand Tajhiz Sahand, Iran) for 24 hours at $-65^{\circ} \mathrm{C}$ and a reduced pressure of 190 mtorr [19].

The dried foams were powdered with a mixer (Kinematica AG, Microtron MB 550, Luzern, Switzerland), sieved (60 mesh), and put into the dark glasses to prevent light degradations. Samples produced in foam-mat hot-air and freeze-drying methods were labeled as FMHD and FMFD, respectively.

\subsection{Powder Experiments}

2.5.1. Moisture Content. $2 \mathrm{~g}$ of powder samples were accurately weighed (ABJ 220-4M, Kern \& Sohn GmbH, Germany), put into Petri dishes, and forwarded to drying in 
an oven (Binder, USA) at $105^{\circ} \mathrm{C}$ for 4 hours [16]. The moisture content was determined using

$$
\% \text { moisture }=\frac{W_{2}-W_{3}}{W_{2}-W_{1}} \times 100,
$$

where $W_{1}$ is wet plate weight $(\mathrm{g}), W_{2}$ is wet plate weight with its sample (wet) (g), and $W_{3}$ is plate weight with its sample (dry) (g).

2.5.2. Flowability and Cohesiveness of Powders. The flowability and cohesiveness of powders were evaluated in terms of Carr's index (CI) and Hausner ratio (HR), respectively [20]. The bulk and tapped densities were calculated according to the method presented by Sharifi et al. [1]. The CI was determined using equation (5). According to Carr's index, flowability classified as very good $(<15 \%)$, good $(15 \%-$ $20 \%)$, relatively good $(20 \%-35 \%)$, bad $(35 \%-45 \%)$, and very bad $(>45 \%)$.

$$
\mathrm{CI}=\frac{\rho \text { Tapped }-\rho \text { Bulk }}{\rho \text { Tapped }} \times 100 .
$$

The cohesiveness of powders was determined using equation (6), as low (<1.2), moderate (1.2-1.4), and high (>1.4):

$$
\mathrm{HR}=\frac{\rho \text { Tapped }}{\rho \text { Bulk }}
$$

2.5.3. Rehydration Time. $0.5 \mathrm{~g}$ of powder was added to $50 \mathrm{ml}$ water at $26^{\circ} \mathrm{C}$. The mixture was stirred using a magnet $(7 \mathrm{~mm} \times 2 \mathrm{~mm})$ on a magnetic stirrer (Velp Scientifica, Italy) at $900 \mathrm{rpm}$. The time was recorded using a chronometer until all particles of powder became invisible by the naked eye [21].

2.5.4. Total Phenolic Content. The total phenolic content (TPC) was evaluated using the procedure described by Seerangurayar et al. [13] with some modifications. About $2 \mathrm{~g}$ of the beverage powder sample was dissolved in $100 \mathrm{ml}$ of distilled water. The solution was centrifuged (model: Hermle Z $323 \mathrm{~K}$, Hermle Labortechnik GmbH, Germany) at $10000 \mathrm{rpm}$ for 15 minutes. Following this, $0.3 \mathrm{ml}$ of the supernatant was added to $2.5 \mathrm{ml}$ of Folin-Ciocalteu reagent (10\%), and after 5 minutes, a total of $2 \mathrm{ml}$ sodium carbonate solution $(7.5 \% \mathrm{~W} / \mathrm{V})$ was added to the mixture. After 90 minutes at room temperature, adsorption was read at $725 \mathrm{~nm}$ using a UV/Vis spectrophotometer (Perkin Elmer, Inc., USA, model: Lambda 35). A blank sample was prepared using all reagents in mentioned amounts except powder extract. For this purpose, $0.3 \mathrm{ml}$ deionized water was added to $2.5 \mathrm{ml}$ of Folin-Ciocalteu reagent (10\%), and after adding $2 \mathrm{ml}$ sodium carbonate solution, the absorbance reading was performed. The concentration of the TPC was reported as milligram gallic acid equivalents (GAE) per gram of powder. $50-500$ ppm gallic acid solution was used to prepare the gallic acid calibration curve.
The TPC of mixed fresh extracts was also determined using the protocol described by Shahidi and Naczk (2004) with some modifications [22]. $0.5 \mathrm{ml}$ of aliquot was added to $2.5 \mathrm{ml}$ Folin-Ciocalteu reagent (prediluted in a ratio of $1: 10$ ) and the abovementioned steps were repeated.

2.5.5. Antioxidant Activity. The antioxidant activity was determined using 2,2-diphenyl-1-picrylhydrazyl (DPPH) assay, following the method described by Rigon and Zapata Noreña [23] with some modifications. $1 \mathrm{~g}$ of powder was suspended in $50 \mathrm{ml}$ methanol $(50 \%, \mathrm{v} / \mathrm{v})$. After keeping for 60 minutes at room temperature, the mixture was centrifuged at $3500 \mathrm{rpm}$ for 15 minutes. For the mixed fresh extracts, a $1 \mathrm{ml}$ aliquot was added to $3 \mathrm{ml}$ methanol (50\%, v/v), homogenized using a vortex mixer (Velp, Inc., Italy, model: Classic), and kept for 60 minutes at room temperature in a dark place [23].

To determine the antioxidant activity of the prepared extracts, a $0.1 \mathrm{ml}$ of diluted powder solution or extract was homogenized with $3.9 \mathrm{ml}$ of $60 \mathrm{mM}$ DPPH. Reduced adsorption against a blank (methanol) was monitored using a UV/Visible spectrophotometer (Perkin Elmer, Lambda 35, USA) after 45 minutes at $515 \mathrm{~nm} \mathrm{[23].} \mathrm{The} \mathrm{results} \mathrm{were}$ reported as a percentage of antioxidant activity using

$$
\operatorname{Antioxidant} \operatorname{activity}(\%)=\left(1-\frac{A_{\text {sample }}}{A_{\text {controle }}}\right) \times 100 \text {, }
$$

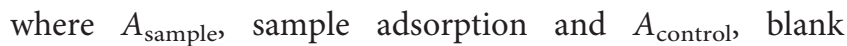
adsorption.

2.5.6. Color Measurement. Color measurement was conducted with the image processing method, using ImageJ processing software (version 1.42e, USA). The high-resolution images of powders were taken using a Canon PowerShot G3 digital camera placed in the upper side of a wooden box equipped with two illumination sources, at a distance of $22 \mathrm{~cm}$ from the sample [24]. The $L *, a *$, and $b *$ values were determined.

2.5.7. Sensory Evaluation. Sensory evaluation of samples was performed using the method described by Feguš et al. [25] with some modifications. The evaluation was performed with 15 panelists. The red beetroot extract-based beverages were evaluated in terms of color, taste, aroma, mouthfeel, and total acceptance using a five-point hedonic scale method and 1-5 scoring level. Score 1 indicates very bad, 2 bad, 3 moderate, 4 good, and 5 very good. Each of the samples was served to panelists in $50 \mathrm{ml}$ glass cups, labeled with 3-digit randomized numbers. In order to prevent sensory disturbances, panelists were asked to rinse their mouth after each sample evaluation.

2.6. Statistical Analysis. For statistical analysis, an analysis of variance (ANOVA) was used, and a comparison of means was done using the Tukey test at $95 \%$ confidential level $(p \leq 0.05)$ using Minitab 18/1 statistical software (Minitab 
Inc., Torre Sul Paraíso, Brazil). Experiments were done at three replications, and mean \pm SD was reported.

\section{Result and Discussions}

3.1. Extracts Analysis. The fresh mixture of extracts had the moisture content of $89 \% \pm 0.17$, total soluble solids of $11.4 \pm 0.09$ degree Brix, and $\mathrm{pH}$ of $5.35 \pm 0.00$. Addition of 10,20 , and $30 \%$ maltodextrin caused total soluble solids of $19.8 \pm 0.03,29.7 \pm 0.01$, and $39.2 \pm 0.07^{\circ} \mathrm{Bx}$, respectively.

\subsection{Foam Analysis}

3.2.1. Foam Expansion. Upon application of different percentages of $\mathrm{MD}$, it was shown that the MD variable had a significant effect on foam expansion $(p \leq 0.05)$ (Figure $1(\mathrm{a})$ ). Generally, the foam expansion decreased as the MD level increased, indicating the low capacity of the mixture to allow air into its structure. High-viscosity samples prevent air trapping inside the foam structure during mechanical stirring [26]. Azizpour et al. [27] also stated that foam expansion of cherry foam decreased as viscosity increased.

3.2.2. Foam Density. In general, the foam density of samples increased as the MD level increased $(p \leq 0.05)$ (Figure 1(b)). These data are compatible with the result of foam expansion, as the least density is related to the sample with the highest foam expansion and vice versa. Similarly, according to the results reported in foam-mat drying of sour cherry, the density of produced foam increased significantly, as methyl cellulose concentration increased $(p \leq 0.05)$. The entry of air into the foam structure increases as the surface tension decreases and leads to a reduction in the density [28].

3.2.3. Foam Stability. Foam stability shows how long the foam can extend without liquid drainage [28]. The MD variable had a significant effect on foam stability $(p \leq 0.05)$ (Figure 1(c)). Foam stability of samples increased as the MD level increased, but at the MD concentration of $30 \% \mathrm{w} / \mathrm{w}$, a significant decrease in the foam stability was observed $(p \leq 0.05)$. The creation of a network structure in the foam bulk phase, which occurs at higher viscosity of the aqueous phase, leads to producing a more stable foam with interfacial walls not easily breaking [29]. Reduced foam stability at an MD level higher than 20\% was also reported by Phaechamud et al. [30] in the foam-mat drying of malabar tamarind extract.

\subsection{Powder Experiments}

3.3.1. Moisture Content. The MD level and the interaction of MD and the drying method had a significant effect on the moisture content of samples $(p \leq 0.05)$. Moisture content in FMFD powders ranged from $8.64 \%$ to $3.28 \%$ and $6.95 \%$ to $4.83 \%$ in FMHD powders (Table 1). Similar observations were also made in the cases of apple juice powder and yacon juice powder where the moisture content depend on the drying method [31]. Generally, the moisture content of powders decreased as the MD level increased. As previously stated by Tchabo et al. [32] and Ekpong et al. [33], increased carbohydrate concentration may cause an increase in sample solids, a decrease in the total volume of moisture to be evaporated, and a reduction in the moisture content.

3.3.2. Rehydration Time. The drying method, MD level, and interaction of these variables had significant effects on the rehydration time of powders $(p \leq 0.05)$. Powders containing $20 \% \mathrm{MD}$ had the lowest rehydration time in both drying methods (Table 1), which contributed to its good foam expansion and stability. On average, FMFD powders had lower rehydration time than FMHD powders. The higher porosity of freeze-dried products plays an important role in their reconstitution properties [34].

3.3.3. Flowability and Cohesiveness of Powders. The flowability of a powder is used to determine the free-flow properties of the powder. An appropriate flow of powder is important for both consumers and manufacturers [34]. Asokapandian et al. [35] ascribed the free-flowing properties of foam-dried powder to the air incorporated during foaming, along with the foaming and stabilizing agents, which is also confirmed by this study. According to Carr's index, only the FMHD beverage powder containing 20\% MD had good flowability, and the others had medium flowability (Table 1). An increased glass transition temperature concomitant with an increased MD level can caused a reduction in hygroscopicity and elevation in the flowability of powders [36].

The higher Hausner ratio means that the powder is more cohesive and has less ability to flow freely [34]. The cohesiveness of the beverage powders was medium in all the treatments (Table 1). The cohesiveness of powder particles is mostly affected by interparticle forces and also other factors such as mechanical interlocking [36].

3.3.4. Total Phenolic Content. The total phenolic content of fresh extracts mixture had $8.5 \pm 0.71 \mathrm{mg}$ GAE/g dry weight. The drying method, MD level, and interaction of these variables had significant effects on the TPC of the produced powders $(p \leq 0.05)$. The control beverage powders $(0 \% \mathrm{MD}$ powders) had higher TPC than MD-added powders (Figure 2(a)). A similar trend of decreased TPC with an increase in carrier concentration was observed by Seerangurayar et al. [13] and Mishra et al. [37] for foam-mat freeze-dried date powder and spray-dried amla juice powder, respectively. This decrease in TPC is attributed to the dilution effect of carrier agents [13].

On an average, FMHD powders had higher TPC than FMFD powders. Different drying methods in different foods may have caused different results on their phenolic content. Some studies had shown that heat treatment caused an increase in the TPC in some food samples such as dry apricots and dry raisins [38]. Shokry [39] reported that the drying process increased the phenolic content of red 


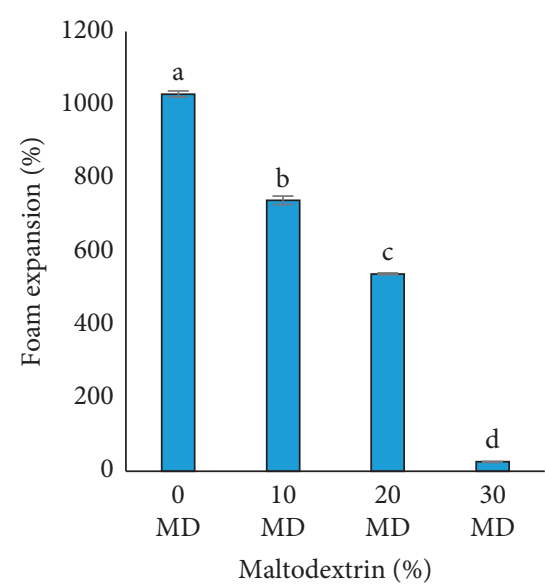

(a)

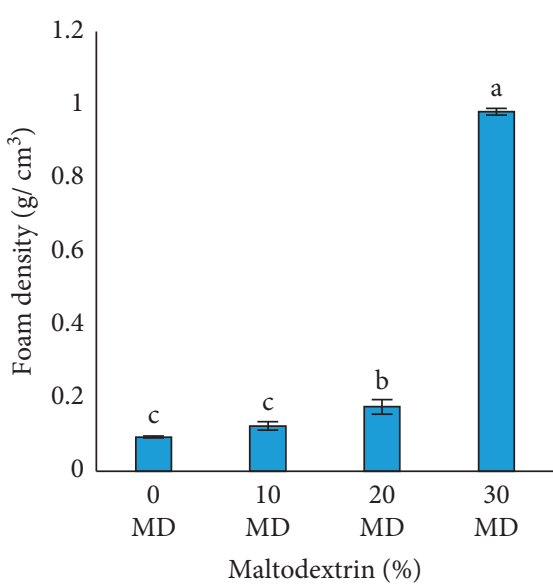

(b)

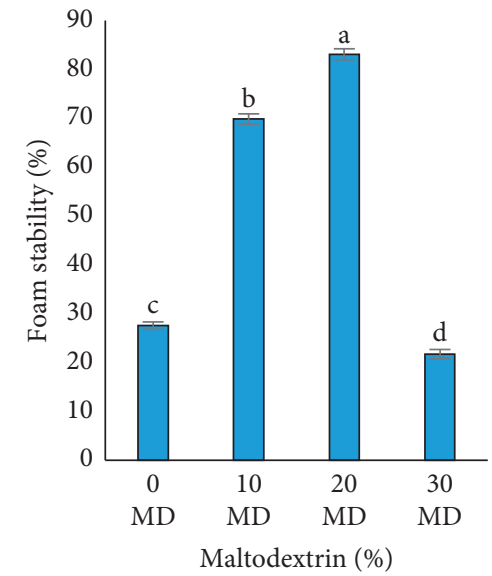

(c)

Figure 1: The effect of maltodextrin concentration on: (a) foam expansion (\%), (b) foam density $\left(\mathrm{g} / \mathrm{cm}^{3}\right)$, and (c) foam stability (\%) of the red beetroot extract-based foams. Mean \pm standard deviation $(n=3)$. Different small letters on each column show significant statistical differences.

TABLE 1: Physical properties of the foam-mat-dried instant beverage powders based on red beetroot extract.

\begin{tabular}{lccccc}
\hline Drying method & MD (\%) & Moisture content (\%) & Carr's index (\%) & Hausner ratio & Rehydration time (s) \\
\hline \multirow{2}{*}{ FMFD } & 0 & $8.64 \pm 0.71^{\mathrm{a}}$ & $25.02 \pm 0.35^{\mathrm{a}}$ & $1.33 \pm 0.006^{\mathrm{a}}$ & $35.63 \pm 0.55^{\mathrm{c}}$ \\
& 10 & $7.5 \pm 0.38^{\mathrm{ab}}$ & $22.38 \pm 0.32^{\mathrm{a}}$ & $1.29 \pm 0.005^{\mathrm{a}}$ & $33.05 \pm 1^{\mathrm{d}}$ \\
& 20 & $4.59 \pm 0.74^{\mathrm{cd}}$ & $20.27 \pm 0.67^{\mathrm{a}}$ & $1.25 \pm 0.01^{\mathrm{a}}$ & $29.03 \pm 1^{\mathrm{e}}$ \\
& 30 & $3.28 \pm 0.5^{\mathrm{d}}$ & $21.85 \pm 0.51^{\mathrm{a}}$ & $1.28 \pm 0.008^{\mathrm{a}}$ & $40.52 \pm 1.21^{\mathrm{b}}$ \\
\hline FMHD & 0 & $6.95 \pm 0.89^{\mathrm{ab}}$ & $24.15 \pm 0.54^{\mathrm{a}}$ & $1.32 \pm 0.009^{\mathrm{a}}$ & $34.03 \pm 0.96^{\mathrm{cd}}$ \\
& 10 & $6.08 \pm 0.79^{\mathrm{bc}}$ & $22.38 \pm 0.20^{\mathrm{a}}$ & $1.29 \pm 0.003^{\mathrm{a}}$ & $35.89 \pm 0.28^{\mathrm{c}}$ \\
& 20 & $5.04 \pm 0.53^{\mathrm{cd}}$ & $19.37 \pm 0.56^{\mathrm{a}}$ & $1.24 \pm 0.009^{\mathrm{a}}$ & $30.51 \pm 0.5^{\mathrm{e}}$ \\
\hline
\end{tabular}

Mean \pm standard deviation $(n=3)$. Means with different letters in each column differ from each other significantly $(p \leq 0.05)$. FMFD: foam-mat freeze-drying, FMHD: foam-mat hot-air drying, and MD: maltodextrin.

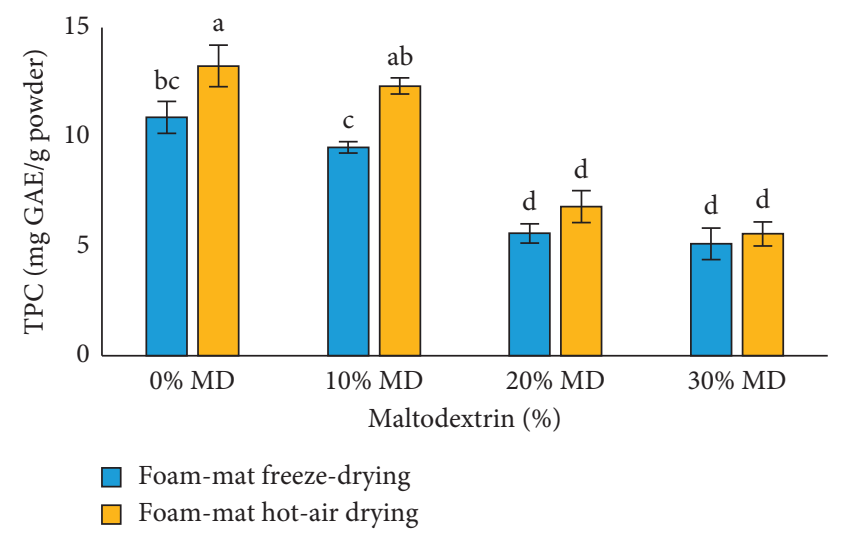

(a)

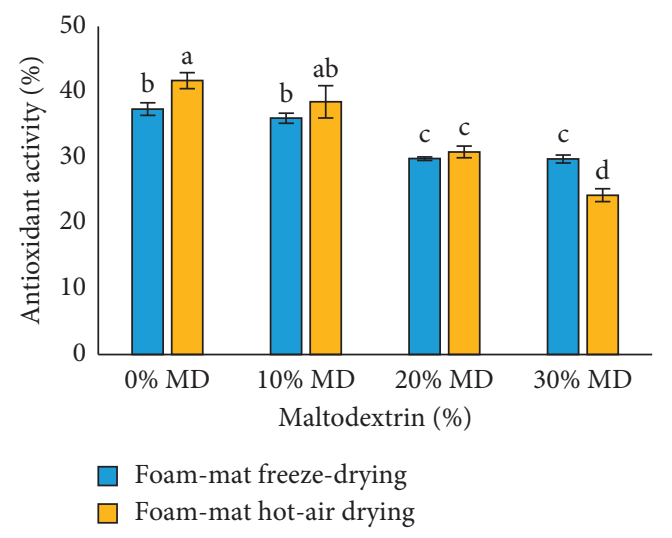

(b)

FIGURE 2: Effect of the drying method and maltodextrin concentration on the chemical properties of foam-mat-dried instant beverage powders based on red beetroot extract. (a) TPC and (b) antioxidant activity. Mean \pm standard deviation $(n=3)$. Different small letters on each column show significant statistical differences.

beetroot powders. Torres et al. [40] reported a 33\% increase in the phenolic content of quince pulp after cooking. According to the research, the thermal hydrolyzation during thermal processing is attributed to an elevation in quercetin content of cooked quince [40].
3.3.5. Antioxidant Activity. Statistical analysis of independent variables showed that the drying method had no significant effect on the antioxidant activity of powders $(p>0.05)$, but the MD concentration and also interaction of the variables had significant effects on this property 
TABLE 2: Effects of different drying methods and MD levels on color values $\left(L^{*}, a^{*}\right.$, and $\left.b^{*}\right)$ of foam-mat-dried instant beverage powders based on red beetroot extract, and sensory properties of the prepared beverages.

\begin{tabular}{|c|c|c|c|c|c|c|c|c|c|}
\hline $\begin{array}{l}\text { Drying } \\
\text { method }\end{array}$ & $\begin{array}{l}\text { MD } \\
(\%)\end{array}$ & $L^{*}$ & $a^{*}$ & $b^{*}$ & Color & Taste & Aroma & Mouthfeel & $\begin{array}{c}\text { Total } \\
\text { acceptance }\end{array}$ \\
\hline \multirow{4}{*}{ FMFD } & 0 & $10.32 \pm 0.03^{h}$ & $22.2 \pm 0.32^{\mathrm{e}}$ & $1.17 \pm 0.06^{\mathrm{g}}$ & $3 \pm 0.76^{\mathrm{cd}}$ & $4.25 \pm 1.04^{\mathrm{a}}$ & $4.5 \pm 0.53^{\mathrm{a}}$ & $3.87 \pm 0.6^{\mathrm{a}}$ & $4 \pm 0.53^{\mathrm{ab}}$ \\
\hline & 10 & $26.82 \pm 0.05^{\mathrm{f}}$ & $43.87 \pm 1.81^{\mathrm{d}}$ & $3.99 \pm 0.01^{\mathrm{f}}$ & $3.13 \pm 0.64^{\mathrm{bcd}}$ & $4.25 \pm 0.7^{\mathrm{a}}$ & $3.88 \pm 0.64^{\mathrm{abc}}$ & $3.87 \pm 1^{\mathrm{a}}$ & $4.13 \pm 0.64^{\mathrm{ab}}$ \\
\hline & 20 & $44.11 \pm 0.01^{\mathrm{b}}$ & $59.38 \pm 0.48^{\mathrm{a}}$ & $4.27 \pm 0.04^{\mathrm{e}}$ & $4.38 \pm 0.52^{\mathrm{a}}$ & $3.63 \pm 0.91^{\mathrm{ab}}$ & $4.25 \pm 0.71^{\mathrm{ab}}$ & $4.5 \pm 0.53^{\mathrm{a}}$ & $4.75 \pm 0.46^{\mathrm{a}}$ \\
\hline & 30 & $47.78 \pm 0.07^{\mathrm{a}}$ & $58.29 \pm 0.19^{\mathrm{a}}$ & $4.35 \pm 0.05^{\mathrm{e}}$ & $4.5 \pm 0.53^{\mathrm{a}}$ & $3.13 \pm 0.83^{\mathrm{ab}}$ & $3.5 \pm 0.76^{\mathrm{abc}}$ & $4.12 \pm 0.64^{\mathrm{a}}$ & $3.5 \pm 1.07^{\mathrm{ab}}$ \\
\hline \multirow{4}{*}{ FMHD } & 0 & $25.69 \pm 0.09^{g}$ & $42.3 \pm 0.44^{\mathrm{d}}$ & $8.87 \pm 0.04^{\mathrm{d}}$ & $2.63 \pm 0.52^{\mathrm{d}}$ & $3.25 \pm 0.89^{\mathrm{ab}}$ & $3.25 \pm 0.71^{\mathrm{bc}}$ & $3.5 \pm 0.8^{\mathrm{a}}$ & $3.25 \pm 0.89^{\mathrm{b}}$ \\
\hline & 10 & $33.13 \pm 0.03^{\mathrm{e}}$ & $47.91 \pm 1.13^{\mathrm{c}}$ & $9.58 \pm 0.16^{c}$ & $2.88 \pm 0.64^{\mathrm{cd}}$ & $3 \pm 0.93^{\mathrm{ab}}$ & $3.13 \pm 0.83^{b c}$ & $3.63 \pm 0.74^{\mathrm{a}}$ & $3.38 \pm 0.74^{\mathrm{b}}$ \\
\hline & 20 & $38.76 \pm 0.16^{\mathrm{d}}$ & $53.41 \pm 0.35^{\mathrm{b}}$ & $9.86 \pm 0.06^{\mathrm{b}}$ & $4.13 \pm 0.64^{\mathrm{ab}}$ & $2.87 \pm 0.83^{\mathrm{b}}$ & $3.13 \pm 1^{\mathrm{bc}}$ & $4.25 \pm 0.76^{\mathrm{a}}$ & $3.75 \pm 0.89^{\mathrm{ab}}$ \\
\hline & 30 & $40.16 \pm 0.01^{\mathrm{c}}$ & $51.53 \pm 0.2^{\mathrm{b}}$ & $10.9 \pm 0.09^{\mathrm{a}}$ & $3.87 \pm 0.83^{\mathrm{abc}}$ & $2.5 \pm 0.76^{\mathrm{b}}$ & $2.88 \pm 0.83^{\mathrm{c}}$ & $4 \pm 0.53^{\mathrm{a}}$ & $3.25 \pm 1.04^{\mathrm{b}}$ \\
\hline
\end{tabular}

Means with different letters in each column differ significantly $(p \leq 0.05)$. FMFD: foam-mat freeze-drying, FMHD: foam-mat hot-air-drying, and MD: maltodextrin

$(p \leq 0.05)$. The fresh extract mixture had antioxidant activity of $30.97 \%$. The higher concentration of MD resulted in the lower antioxidant capacity of the beverage powders (Figure 2(b)). Similar results were reported in cranberry juice powders obtained with different carrier agents [41].

Antioxidant activity depends on the process [14]. On an average, FMHD powders had higher antioxidant activity than FMFD powders. It is also believed that higher phenolic content at higher drying temperatures might be related to higher antioxidant activity [42]. A positive correlation between the TPC and antioxidant capacity of cranberry powders was also reported [41].

3.3.6. Color Measurement. The coordinate $L *$ indicates the lightness of powders. According to Table 2, an increase in the MD concentration caused an increase in the $L *$ of produced powders too. Similar results were also reported in cranberry powder [41], date powder [13], and muskmelon powder [35]. According to Ekpong et al. [33], an increase in the lightness of samples might be a reflection of pale, white color of MD powder.

The coordinate $a *$ is an indication of greenness/redness. The highest $a *$ values reported for powders contain 20\% MD (Table 2). As represented in Figure 3, the FMFD control sample ( $0 \%$ maltodextrin) had a dark brown color which represented the lowest $a *$ in image processing that might be related to its high moisture content. According to Gokhale and Lele [43], beetroot contains a high amount of red pigments that appeared dark when the color of its surface was measured (low $L *$ ), and so, lower values of coordinate $a *$ are recorded. Increased MD concentration to $30 \%$ has led to a decrease in the $a *$ value. This decreased $a *$ values may be related to the inert white color of MD.

The $b *$ value of beverage powders, as an indication of blueness/yellowness, increased as the MD concentration increased (Table 2). When FMFD and FMHD beverage powders were compared, FMHD samples had more $b *$. The higher $b *$ values in FMHD powders can be related to their higher drying temperature. Increased $b *$ (yellowness) reported in the production of guava powder was ascribed to nonenzymatic browning [44]. Color changes during drying processes may be due to carotenoid degradation and Millard reaction [35].

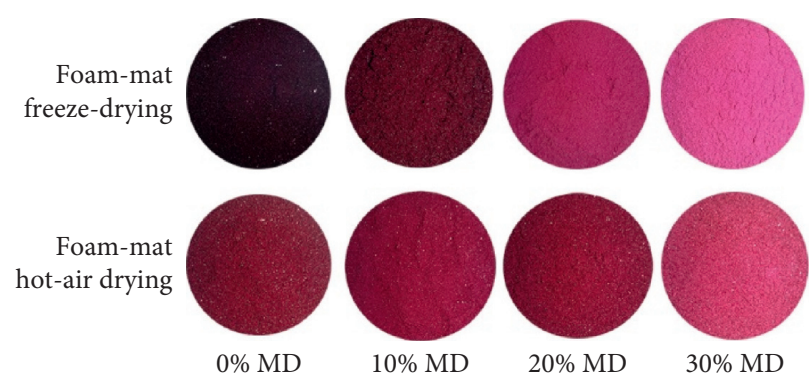

FIgURE 3: The color of foam-mat-dried instant beverage powders based on red beetroot extract; MD, maltodextrin.

3.3.7. Sensory Evaluation. Beverages prepared with FMFD powders gained better color scores than those of FMHD samples. Overall (Table 2), similar to Ekpong et al. [33], panelists reported better color as maltodextrin concentration increased $(p \leq 0.05)$. In general, as MD concentration increased, the taste of beverages decreased, and samples received fewer points in the hedonic scale. Similarly, Moura Neto et al. [45] observed a significant reduction in the flavor of reconstituted juice of yellow mombin (Spondias mombin L.) atomized powder attributed to the use of a high concentration of maltodextrin, which was also probable in the case of reduction of the flavor in acerola and seriguela mixed powder [46].

The aroma of the beverages prepared with FMFD powders were more intense than FMHD beverages, which can be due to less temperature used in the freeze-drying method. Statistical analysis of the sensory evaluation of beverages had shown no differences in terms of mouthfeel $(p>0.05)$ (Table 2).

According to Table 2, there was a significant difference between beverages in terms of total acceptance $(p \leq 0.05)$. Overall, prepared beverages with FMFD powders could receive more points in the hedonic scale than beverages prepared with FMHD powders. The highest hedonic scores in terms of total acceptance in FMHD and FMFD samples belonged to powders contain $20 \% \mathrm{MD}$.

\section{Conclusion}

In the present study, the beetroot extract-based beverage powders were produced using different concentrations of MD to evaluate some of the physicochemical properties of 
the powders obtained after foam-mat freeze- and hot-air drying. Foam experiments showed that as maltodextrin level increased, foam expansion decreased and foam density increased. Foam prepared with $20 \%$ MD had the highest foam stability of $83.08 \%$. According to the powder experiments, the moisture content of powders decreased as the MD level increased. In both drying methods, powders containing 20\% MD had the lowest dissolving time. The highest $a *$ value belonged to $20 \%$ MD samples. FMHD powders had more TPC than FMFD powders. As the MD level increased, the TPC and the antioxidant activity of powders decreased. This study concluded that the powder containing 20\% MD prepared with FMHD was an optimum sample.

\section{Data Availability}

The datasets generated and/or analyzed during the current study are available from the corresponding author on reasonable request.

\section{Conflicts of Interest}

The authors declare no conflicts of interest.

\section{References}

[1] A. Sharifi, M. Niakousari, A. Maskooki, and S. A. Mortazavi, "Effect of spray drying conditions on the physicochemical properties of barberry (Berberis vulgaris) extract powder," International Food Research Journal, vol. 22, no. 6, pp. 2364-2370, 2015.

[2] S. Akan, N. Tuna Gunes, and M. Erkan, "Red beetroot: health benefits, production techniques, and quality maintaining for food industry," Journal of Food Processing and Preservation, vol. 45, no. 10, Article ID e15781, 2021.

[3] T. Clifford, G. Howatson, D. West, and E. Stevenson, "The potential benefits of red beetroot supplementation in health and disease," Nutrients, vol. 7, no. 4, pp. 2801-2822, 2015.

[4] M. L. Ng and R. Sulaiman, "Development of beetroot (Beta vulgaris) powder using foam mat drying," LebensmittelWissenschaft \& Technologie, vol. 88, no. 1, pp. 80-86, 2018.

[5] B. Tobolková, M. Polovka, L. Daško, E. Belajová, and J. Durec, "Evaluation of qualitative changes of apple-beetroot juice during long-term storage at different temperatures," Journal of Food Measurement and Characterization, vol. 14, no. 5, pp. 3381-3388, 2020.

[6] A. Gironés-Vilaplana, N. Baenas, D. Villaño, and D. A. Moreno, Iberian-American Fruits Rich in Bioactive Phytochemicals for Nutrition and Health, LIMENCOP S.L., Alicante, Spain, 2014.

[7] R. Hamidpour, M. Hamidpour, S. Hamidpour, and M. Shahlari, "Cinnamon from the selection of traditional applications to its novel effects on the inhibition of angiogenesis in cancer cells and prevention of alzheimer's disease, and a series of functions such as antioxidant, anticholesterol, antidiabetes, antibacterial, antifungal, nematicidal, acaracidal, and repellent activities," Journal of Traditional and Complementary Medicine, vol. 5, no. 2, pp. 66-70, 2015.

[8] S. Nabavi, A. Di Lorenzo, M. Izadi, E. Sobarzo-Sánchez, M. Daglia, and S. Nabavi, "Antibacterial effects of cinnamon: from farm to food, cosmetic and pharmaceutical industries," Nutrients, vol. 7, no. 9, pp. 7729-7748, 2015.
[9] R. V. de Barros Fernandes and D. A. Botrel, "Foam-mat drying of vegetables," in Handbook of Drying of Vegetables and Vegetable Products, M. Zhang, B. Bhandari, and Z. Fang, Eds., pp. 135-149, CRC, New York, NY, USA, 2017.

[10] D. Langevin, "Aqueous foams and foam films stabilised by surfactants. Gravity-free studies," Comptes Rendus Mecanique, vol. 345, no. 1, pp. 47-55, 2017.

[11] O. S. Qadri, A. K. Srivastava, and B. Yousuf, "Trends in foam mat drying of foods: special emphasis on hybrid foam mat drying technology," Critical Reviews in Food Science and Nutrition, vol. 60, no. 10, pp. 1667-1676, 2020.

[12] Y. Abbaspour-Gilandeh, M. Kaveh, H. Fatemi, J. L. Hernández-Hernández, A. Fuentes-Penna, and M. Hernández-Hernández, "Evaluation of the changes in thermal, qualitative, and antioxidant properties of Terebinth (Pistacia atlantica) fruit under different drying methods," Agronomy, vol. 10, no. 9, p. 1378, 2020.

[13] T. Seerangurayar, A. Manickavasagan, A. M. Al-Ismaili, and Y. A. Al-Mulla, "Effect of carrier agents on physicochemical properties of foam-mat freeze-dried date powder," Drying Technology, vol. 36, no. 11, pp. 1292-1303, 2018.

[14] T. Iasnaia Maria de Carvalho, T. Y. K. Nogueira, M. A. Mauro et al., "Dehydration of jambolan [Syzygium cumini (L.)] juice during foam mat drying: quantitative and qualitative changes of the phenolic compounds," Food Research International, vol. 102, pp. 32-42, 2017.

[15] A. Slavov, V. Karagyozov, P. Denev, M. Kratchanova, and C. Kratchanov, "Antioxidant activity of red beet juices obtained after microwave and thermal pretreatments," Czech Journal of Food Sciences, vol. 31, no. 2, pp. 139-147, 2013.

[16] AOAC, Official Methods of Analysis, Association of Analytical Chemists, Gaithersburg, MD, USA, 18th edition, 2005.

[17] M. Azizpour, M. Mohebbi, M. Yolmeh, E. Abbasi, and M. M. Sangatash, "Effects of different hydrocolloids on foaming properties of shrimp puree: a cluster analysis," Journal of Food Measurement and Characterization, vol. 11, no. 4, pp. 1892-1898, 2017.

[18] K. G. Marinova, E. S. Basheva, B. Nenova et al., "Physicochemical factors controlling the foamability and foam stability of milk proteins: sodium caseinate and whey protein concentrates," Food Hydrocolloids, vol. 23, no. 7, pp. 1864-1876, 2009.

[19] F. Jamdar, S. Ali Mortazavi, M. Reza Saiedi Asl, and A. Sharifi, "Physicochemical properties and enzymatic activity of wheat germ extract microencapsulated with spray and freeze drying," Food Sciences and Nutrition, vol. 9, no. 2, pp. 1192-1201, 2021.

[20] N. Jinapong, M. Suphantharika, and P. Jamnong, "Production of instant soymilk powders by ultrafiltration, spray drying and fluidized bed agglomeration," Journal of Food Engineering, vol. 84, no. 2, pp. 194-205, 2008.

[21] S. Darniadi, P. Ho, and B. S. Murray, "Comparison of blueberry powder produced via foam-mat freeze-drying versus spray-drying: evaluation of foam and powder properties," Journal of the Science of Food and Agriculture, vol. 98, no. 5, pp. 2002-2010, 2018.

[22] F. Shahidi and M. Naczk, Phenolics in Food and Nutraceuticals, CRC Press, Boca Raton, FL, USA, 2nd edition, 2004.

[23] R. T. Rigon and C. P. Zapata Noreña, "Microencapsulation by spray-drying of bioactive compounds extracted from blackberry (Rubus fruticosus)," Journal of Food Science \& Technology, vol. 53, no. 3, pp. 1515-1524, 2016. 
[24] K. León, D. Mery, F. Pedreschi, and J. León, "Color measurement in $L^{*} a^{*} b^{*}$ units from RGB digital images," Food Research International, vol. 39, no. 10, pp. 1084-1091, 2006.

[25] U. Feguš, U. Žigon, M. Petermann, and Ž Knez, "Effect of drying parameters on physiochemical and sensory properties of fruit powders processed by PGSS-, vacuum- and spraydrying," Acta Chimica Slovenica, vol. 62, no. 2, pp. 479-487, 2015.

[26] A. A. Karim and C. C. Wai, "Foam-mat drying of starfruit (Averrhoa carambola L.) purée. Stability and air drying characteristics," Food Chemistry, vol. 64, no. 3, pp. 337-343, 1999.

[27] M. Azizpour, M. Mohebbi, M. Hossein Haddad Khodaparast, and M. Varidi, "Optimization of foaming parameters and investigating the effects of drying temperature on the foammat drying of shrimp (Penaeus indicus)," Drying Technology, vol. 32, no. 4, pp. 374-384, 2014.

[28] E. Abbasi and M. Azizpour, "Evaluation of physicochemical properties of foam mat dried sour cherry powder," Lebensmittel-Wissenschaft und -Technologie-Food Science and Technology, vol. 68, no. 1, pp. 105-110, 2016.

[29] M. R. Salahi, M. Mohebbi, and M. Taghizadeh, "Foam-mat drying of cantaloupe (Cucumis melo): optimization of foaming parameters and investigating drying characteristics," Journal of Food Processing and Preservation, vol. 39, no. 6, pp. 1798-1808, 2015.

[30] T. Phaechamud, K. Sarunyakasitrin, and C. Choncheewa, "Instant powder of malabar tamarind fruit extract prepared by foam-mat method," Advanced Materials Research, vol. 506, no. 1, pp. 351-354, 2012.

[31] A. Michalska and K. Lech, "The effect of carrier quantity and drying method on the physical properties of apple juice powders," Beverages, vol. 4, no. 1, 2018.

[32] W. Tchabo, Y. Ma, G. K. Kaptso et al., "Carrier effects on the chemical and physical properties of freeze-dried encapsulated mulberry leaf extract powder," Acta Chimica Slovenica, vol. 65, no. 4, pp. 823-835, 2018.

[33] A. Ekpong, W. Phomkong, and E. Onsaard, "The effects of maltodextrin as a drying aid and drying temperature on production of tamarind powder and consumer acceptance of the powder," International Food Research Journal, vol. 23, no. 1, pp. 300-308, 2016.

[34] G. Caliskan and S. N. Dirim, "The effect of different drying processes and the amounts of maltodextrin addition on the powder properties of sumac extract powders," Powder Technology, vol. 287, no. 1, pp. 308-314, 2016.

[35] S. Asokapandian, S. Venkatachalam, G. J. Swamy, and K. Kuppusamy, "Optimization of foaming properties and foam mat drying of muskmelon using soy protein," Journal of Food Process Engineering, vol. 39, no. 6, pp. 692-701, 2016.

[36] T. Seerangurayar, A. Manickavasagan, A. M. Al-Ismaili, and Y. A. Al-Mulla, "Effect of carrier agents on flowability and microstructural properties of foam-mat freeze dried date powder," Journal of Food Engineering, vol. 215, no. 1, pp. 33-43, 2017.

[37] P. Mishra, S. Mishra, and C. L. Mahanta, "Effect of maltodextrin concentration and inlet temperature during spray drying on physicochemical and antioxidant properties of amla (Emblica officinalis) juice powder," Food and Bioproducts Processing, vol. 92, no. 3, pp. 252-258, 2014.

[38] N. Izli, G. Izli, and O. Taskin, "Influence of different drying techniques on drying parameters of mango," Food Science and Technology, vol. 37, no. 4, pp. 604-612, 2017.
[39] A. M. Shokry, "Effect of different drying methods on red beet (Beta vulgaris) quality," International Journal of Current Research, vol. 10, no. 4, pp. 68189-68193, 2018.

[40] C. A. Torres, G. Sepúlveda, and A. A. Concha-Meyer, "Effect of processing on quality attributes and phenolic profile of quince dried bar snack," Journal of the Science of Food and Agriculture, vol. 99, no. 5, pp. 2556-2564, 2019.

[41] A. Michalska-Ciechanowska, J. Majerska, J. Brzezowska, A. Wojdyło, and A. Figiel, "The influence of maltodextrin and inulin on the physico-chemical properties of cranberry juice powders," Chemical Engineering, vol. 4, no. 1, p. 12, 2020.

[42] S. Roshanak, M. Rahimmalek, and S. A. H. Goli, "Evaluation of seven different drying treatments in respect to total flavonoid, phenolic, vitamin $\mathrm{C}$ content, chlorophyll, antioxidant activity and color of green tea (Camellia sinensis or C. assamica) leaves," Journal of Food Science \& Technology, vol. 53, no. 1, pp. 721-729, 2016.

[43] S. V. Gokhale and S. S. Lele, "Betalain content and antioxidant activity of beta vulgaris: effect of hot air convective drying and storage," Journal of Food Processing and Preservation, vol. 38, no. 1, pp. 585-590, 2014.

[44] T. Mahendran, "Physico-chemical properties and sensory characteristics of dehydrated guava concentrate: effect of drying method and maltodextrin concentration," Tropical Agricultural Research and Extension, vol. 13, no. 2, pp. 48-54, 2011.

[45] L. G. D. Moura Neto, É. M. D. F. F. Rocha, M. R. A. Afonso, S. Rodrigues, and J. M. C. D. Costa, "Physicochemical and sensory evaluation of yellow mombin (Spondias mombin L.) atomized powder," Revista Caatinga, vol. 28, no. 4, pp. 244-252, 2015.

[46] C. M. C. M. Ribeiro, L. C. d. S. A. Magliano, M. M. A. d. Costa, T. K. A. Bezerra, F. L. H. d. Silva, and M. I. S. Maciel, "Optimization of the spray drying process conditions for acerola and seriguela juice mix," Food Science and Technology, vol. 39, no. 7, pp. 48-55, 2018. 